\title{
LE PROBLEME D'EQUIVALENCE DE TERMINOLOGIE SUR « LES BIENS » ET « LE PATRIMOINE » DANS LE CODE CIVIL FRANÇAIS ET JAPONAIS
}

\author{
Yuki HORIE \\ Adam Mickiewicz University \\ Institute of Linguistics \\ pupu720205@gmail.com
}

Résumé : Au Japon, dans l'ère Meiji en 1868, la traduction du Code Napoléon, qui était considéré comme le droit le plus complet à ce moment-là, fut réalisée. La création du Code civil japonais par la traduction du Code Napoléon a donné une occasion aux Japonais de connaître des idées nouvelles qui n'existaient pas à cette époque-là. Cette introduction de nouvelles notions à causé de créer un grand nombre de néologismes. À cette époque-là, la terminologie «biens »a étée traduite comme 《財産 zaisan» et la terminologie «patrimoine» comme 《資産 shisan 》 par Mitsukuri Rinsho 箕作麒麟 et Gustave Emile Boissonade de Fontarabie. Aujourd'hui «財産 zaisan» est accepté comme l'équivalence des «biens », par contre la traduction $d u$ « patrimoine » sont très variés ; « 家産 kasan 》《資産 shisan》《財産体 zaisantai 》《財物 zaibutsu 》 selon les 
traducteurs. Dans cet article, nous allons d'abord observer le Code civil japonais du point de vue historique, ensuite le concept sur «les biens» et «le patrimoine » dans le Code civil français de l'époque, aussi si ce concept français était bien compris et accepté dans le Code civil japonais. À la fin, nous allons examiner quel type de traduction est le plus approprié pour «les biens» et « le patrimoine » à partir de considérations linguistiques.

Mots clés : les biens, le patrimoine, la terminologie, le Code Napoléon, le Code civil japonais.

\section{フランスと日本の民法における les biens と le patrimoine に関するエキ バレンス}

要約：日本の民法は 1868 年にナポレオン法典をもとに作成された。 ナポレオン法典の翻訳をはじめとして行われた日本の民法の作成により、 日本にそれまで存在しなかった新しい概念が導入され、多くの新語が造 語された。その当時箕作麟祥とボワソナードにより、フランス語の biens は「財産」、 patrimoine は「資産」と訳された。今日、「財産」 は biens のエキバレンスとして使用されているが、 patrimoine は翻訳者 により「家産」「資産」「財産体」「財物」などとさまざまな訳語が 当てられている。本論文では、フランス語の biens と patrimoine の概念 を理解し、箕作とボワソナードが翻訳を行った当時の状況をふまえ、言 語的配慮から両語に最も適した翻訳を検討したい。

キーワード : les biens、 le patrimoine、専門用語、ナポレオン法典、日 本の民法。

\section{PROBLEM EKWIWALENCJI TERMINOLOGII DOTYCZĄCEJ PRAWA RZECZOWEGO WE FRANCUSKIM I JAPOŃSKIM KODEKSIE CYWILNYM}

Streszczenie: Niniejszy artykuł porusza problematykę ekwiwalencji terminologii $\mathrm{z}$ zakresu prawa rzeczowego we francuskim oraz japońskim kodeksie cywilnym. W erze Meiji Japonia dokonała modernizacji prawa wzorując się na kodyfikacjach napoleońskich. Kodeks cywilny opracowany we Francji był uważany za najlepszy tekst prawny na świecie i z tego powodu został przetłumaczony na język japoński przez Mitsukuri 10 
Rinsho. W tamtym okresie francuski termin "biens" przetlumaczona na japoński termin “財産 zaisan” a termin “patrimoine” na “資産 shisan”. Ekwiwalenty te zaproponowali 箕作麒麟 Mitsukuri Rinsho i Gustave Emile Boissonade de Fontarabie. Obecnie “財産 zaisan” jest ogólnie przyjętym ekwiwalentem terminu "biens", natomiast ekwiwalenty dla terminu "patrimoine" są następujące: 家産 kasan, 資産 shisan, 財産体 zaisantai, 財物 zaibutsu. W niniejszej pracy autorka omówi pojęcia francuskie i ich ekwiwalenty japońskie z perspektywy historycznej i lingwistycznej.

Slowa kluczowe: mienie, majątek, terminologia, Kodeks Napoleona, Kodeks cywilny francuski

\title{
PROBLEM OF FINDING EQUIVALENCE FOR PROPERTY LAW TERMINOLOGY IN FRENCH AND JAPANESE CIVIL CODES
}

\begin{abstract}
In the Meiji era, Japan was attempting to modernize and Europeanize through legal reforms. At that time in Japan, Napoleonic Code was regarded as the best civil code and was translated into Japanese by Mitsukuri Rinsho. However, bcause of the lack of the dictionary and any material concerning the law, Mitsukuri was forced to coin the new words during the translation. At that time, the French term "biens" was translated in Japanese as “財産 zaisan" and the term “patrimoine” was translated as “資産 shisan” by 箕作麒麟 Mitsukuri Rinsho et Gustave Emile Boissonade de Fontarabie. Today, “財産 zaisan” is accepted as the equivalent for "biens", however the translation of term "patrimoine” is very varied according to the translators: 家産 kasan, 資産 shisan, 財産体 zaisantai, 財物 zaibutsu. In this article, we will first observe the historical perspective of the Japanese Civil Code, then the concept of these two French terms to find the most appropriate translation in Japanese from linguistic point of view.
\end{abstract}

Key words: les biens (property), le patrimoine (heritage), terminology, the Code Napoleon, the Japanese Civil Code. 


\section{Introduction}

« La propriété » est l'un des concepts les plus importants du Code civil. Cependant, dans le Code civil japonais, il n'y a pas de définition concrète sur cette notion. Par exemple, dans le Code civil japonais, il n'est pas clairement noté la différence entre « le patrimoine » et « les biens ». D'autre part, dans le Code civil français, la différence des «biens » et du « patrimoine » est clairement indiquée. En outre, il y a aussi la définition claire du terme "propriété ». Bien que ces trois concepts juridiques soient concernés l'un et l'autre, les sens du "patrimoine » et des « biens » sont constitués dans le Code civil français.

Au Japon, dans l'ère Meiji en 1868, la traduction du Code Napoléon, qui était considéré comme le droit le plus complet à ce momentlà, fut réalisée. La création du Code civil japonais par la traduction du Code Napoléon a donné l'occasion aux Japonais de connaître des idées nouvelles qui n'existaient pas à cette époque-là. Cette introduction de nouvelles notions a entraîné la création d'un grand nombre de néologismes. À l'ère Meiji, le terme «biens » était traduit comme «zaisan 財 産》 et le terme 《patrimoine» était traduit comme 《shisan 資産》par Mitsukuri Rinsho 箕作麒麟 et Gustave Emile Boissonade de Fontarabie $^{1}$. Après la guerre il y avait la tendance à traduire le terme «biens » comme «zai 財» et le terme 《patrimoine» comme 《zaisan 財産》. On accepte actuellement dans l'usage «zaisan 財産» comme la traduction du terme «biens ». Par conséquent, il est devenu un problème de savoir comment le terme « patrimoine » doit être traduit.

Le terme 《patrimoine 》 est traduit comme 《kasan 家産》par Yamaguchi dans le フランス法辞典 (le dictionnaire du droit français) (2002 : 421), par contre dans 法務大臣官房司法法制調査部編フラン ス民法典 (le dictionnaire du Code civil français par le ministre de la Justice, Secrétariat judiciaire dans le Département des enquêtes et des

\footnotetext{
${ }^{1}$ Gustave Emile Boissonade de Fontarabie (1825-1910), un juriste français et professeur de l'Université de Paris
} 
recherches) (1978:14) la traduction du «patrimoine» est 《shisan 資 産》. Autre remarque, Nakamura a traduit ce mot comme «zaisantai 財 産体》dans son フランス法律用語辞典 (le dictionnaire de termes judiciaires français) (1956: 219) et Yokoyama dans sa thèse dans le titre 《財産概念について (sur la notion de propriété)》 a utilisé « zaibutsu 財物》 comme la traduction des 《biens » et 《shisan 資産》 comme la traduction de «patrimoine ». Cependant, aucune traduction n'est officiellement acceptée.

Dans cet article, nous allons d'abord observer le Code civil japonais du point de vue historique, ensuite le concept sur « les biens » et « le patrimoine » dans le Code civil français de l'époque, et aussi si elle était bien comprise et acceptée dans le Code civil japonais. À la fin, nous allons examiner quel type de traduction est le plus approprié à partir des considérations linguistiques.

\section{Histoire du droit japonais}

Dans la seconde moitié du $\mathrm{II}^{\mathrm{e}}$ siècle au Japon, la politicienne Himiko 卑 弥呼 de Yamataikoku 邪馬台国 gouvernait selon la volonté de Dieu. À cette époque, les actes d'abomination contre Dieu étaient traités comme un «crime». Himiko accusait et punissait chaque personne qui avait commis un « crime » par la fustiger « harai » pour apaiser la colère de Dieu. En 645, la centralisation du Japon fut réalisée grâce aux réformes Taika 大化, puis, la transition vers un seul système d'administration aboutit au début du $\mathrm{VII}^{\mathrm{e}}$ siècle. L'empereur a créé un système juridique en 701, qui s'appelle le «Code de Taiho 大宝律令 Taiō ritsuryō». Ce droit était le premier droit au Japon concernant principalement l'organisation administrative et le droit pénal. Quand l'ancien régime Ritsuryo 律令 s'effondra, on essaya par la suite, de régler et de centraliser par le droit écrit pour remplacer l'ère du droit coutumier basé sur un 
système seigneurial. Ce droit peut être divisé en trois systèmes : «droit d'aristocrates », « droit Honjo» et « droit Samurai». (Murakami 2005: 38).

Ce ne fut que dans l'ère Meiji en 1868, par la pression des pays occidentaux, l'initiative pour promouvoir la modernisation du droit a été faite comme un signe du caractère occidental de la civilisation du Japon. Après la consultation de Lorenz von Stein, de ses élèves Albert Mosse et Rudolf Gneist, Hirobumi Ito 伊藤博文 proposa le modèle constitutionnel allemand pour la Constitution japonaise en vigueur. Le projet, rédigé par Hermann Roesler et Albert Mosse, fut par la suite promulgué en tant que Constitution impériale japonaise 大日本帝国憲法 Dainippon teikoku kenpō en 1889, qui fut en vigueur du 29 novembre 1890 au 2 mai 1947 (Mukarami 2005 :22-23).

Par contre, en ce qui concerne le Code civil, la traduction du Code Napoléon, qui était considéré comme le droit le plus complet à ce moment-là, fut réalisée en 1870. Ce travail fut initié par Rinsho Mitsukuri 箕作麒麟. Toutefois, à cette époque au Japon, il n'y avait ni de dictionnaire sur le droit ni de matériaux dans ce domaine, Mitsukuri fut alors forcé d'inventer un grand nombre de néologismes. Cette traduction du Code Napoléon par Mitsukuri fut publiée en 1874 comme les 40 tomes de livres sous le titre de « Les livres du droit français 仏蘭西法律 書 Furansu hōritsusho ».

Ce livre juridique, même si immature et incomplet qu'il fût, reste sans aucun doute un pionnier du droit moderne unifié au Japon. À la suite de la traduction du Code Napoléon, Mitsukuri s'est mis à la réduction du Code civil japonais avec Gustave Emile Boissonade de Fontarabie. Il s'est rendu au Japon en 1873 sur la proposition de Hisanobu Samejima, ministre du Japon, pour accélérer le projet de moderniser et perfectionner le système juridique japonais. Il accepta tout d'abord un engagement de rédaction en français du code pénal et du code de procédure criminelle, qui ont été promulgués après la traduction en japonais et des discussions au Sénat. À partir de 1879, il s'engagea dans la rédaction du projet de code civil qui s'est achevé en 1890 composé de deux parties: Boissonade choisit de s'occuper de la question des biens, tandis 
que ses confrères japonais traitèrent des personnes et du droit de succession. Malheureusement pour lui, les dix années de ses travaux se heurtèrent à une vive opposition de la part des nationalistes japonais et la mise en vigueur prévue pour janvier 1893 fut ajournée. Le Code civil « Boissonade» fut révisé en mars 1893 par une commission extraparlementaire, et retravaillé par des juristes japonais suivant le modèle du Code civil prussien. Mais malgré cette inspiration allemande, il n'en demeure pas moins qu'une grande partie du travail de Boissonade fut conservée. Le Code civil «Boissonade » est appelé en japonais « Kyuminpo (l'ancien Code civil) » (Kawaguchi 2005: 84-85). Le Code civil retravaillé selon le système allemand est appelé 《明治民法 Meiji Mimpō (Code civil de Meiji) », pour le distinguer de «l'ancien Code civil» (Kawaguchi 2005: 287-288).

\section{Sources des néologisme dans le Kyu-minpo comme la traduction des termes français Histoire du droit japo- nais}

Comme mentionné ci-dessus, le Code Napoléon a été rapidement traduit en japonais dans l'ère Meiji. La traduction de la terminologie juridique était extrêmement difficile puisque les concepts tels que «droit civil» et «droit privé » n'existaient pas au Japon. Il était presque impossible d'emprunter les mots qui avaient existé dans la langue japonaise pour exprimer de nouvelles idées, de manière qui soit compréhensible par le public. Arinori Mori, le fonctionnaire du gouvernement Meiji, qui s'est consacré à la modernisation du Japon a écrit que « la langue japonaise ne peut fonctionner sans l'utilisation des caractères chinois (c'est-à-dire que la plupart de mots japonais sont déjà des emprunts lexicaux du chinois), qui est la cause de la faiblesse de cette langue » (Saito 2005: 23. traduction en français par Horie). La conviction de l'impossibilité d'utiliser la langue japonaise surtout dans le monde scientifique était si 
forte qu'il y avait même des idées d'introduire l'anglais comme la langue officielle. Ce point de vue était également partagé par le premier ministre de l'Éducation du Japon. Mori a déclaré lui-même son propre plan dans sa lettre pour William D. Whitney, professeur à l'université de Yale. Quand même, ce professeur américain a écrit dans sa réponse : «Si les Japonais veulent diriger toute la nation vers le progrès de civilisation, ils doivent d'abord améliorer progressivement leur propre langue » (Saito 2005: 25. traduction en français par Horie). Avec la proclamation active par les chercheurs comme Yukichi Fukuzawa, une toute nouvelle terminologie juridique a été créée et cela s'appelle aujourd'hui 《明治語 Meiji go (terminologie Meiji) 》(Saito 2005: 15-20).

La langue d'origine de chaque traduction n'est pas sûre, elle pourrait être le français ou l'allemand, mais aussi le néerlandais, qui a été enseigné au Japon dans la période $E d o$. Même si des mots ont été forgés au cours de la traduction du code civil français en japonais, il est arrivé que ces concepts eussent déjà existé dans la langue japonaise à travers la langue néerlandaise. Par exemple, Nobushige Hozumi 穂 積 陳重 a écrit dans son livre Hoso Yawa 法空夜話 : «Le terme mimpō 民法 a été créé par Mamichi Tsuda 津田真道 en 1868. Parce que le terme est devenu populaire après que Rinsho Mitsukuri 箕作麟祥 l'a utilisé comme une traduction du mot « code civil» français, au début, je pensais qu'il était un néologisme créé par Mitsukuri. Mais lorsque je l'ai interrogé, il a répondu que ce n'était pas son travail, mais qu'il avait emprunté ce terme de Taiseikokuhōron 泰西国宝論 écrit par Tsuda. Lorsque je l'ai interrogé à ce sujet à $T s u d a$, il a répondu qu'il avait créé ce terme comme la traduction du mot néerlandais burgerlykregt » (Saito 2005: 28-30, traduction en français par Horie).

Non seulement la terminologie dans le domaine du droit civil, mais la plupart des mots forgés à cette époque-là ont été composés par des idéogrammes chinois. La première raison est le fait que la langue utilisée dans la recherche scientifique au Japon n'était pas proprement le japonais, mais le chinois adapté au japonais, qui s'appelle kango 漢語. Dans l'ère Meiji, de la même manière il a été utilisé sur le terrain des idées modernes. La deuxième raison est le fait que dans le cas des con- 
cepts abstraits, la formation des noms en regroupant deux ou trois idéogrammes chinois était tout à fait simple. En outre, le kango était une langue étrangère venant de la Chine par la lecture on'yomi (lecture sonore), qui se lisait également par la lecture kun'yomi (lecture sémantique) et qui était suffisamment adapté à la langue japonaise.

4. Kyu-minpo 旧民法 (l'ancien Code civil)

Ci-dessous, je donne comme exemple de l'article $1^{\text {er }}$ du livre «財産編 総則 財産及七物ノ区別 (la propriété règle générale, Les biens et distinction des choses) » de l'ancien Code civil japonais et sa traduction officielle en français.

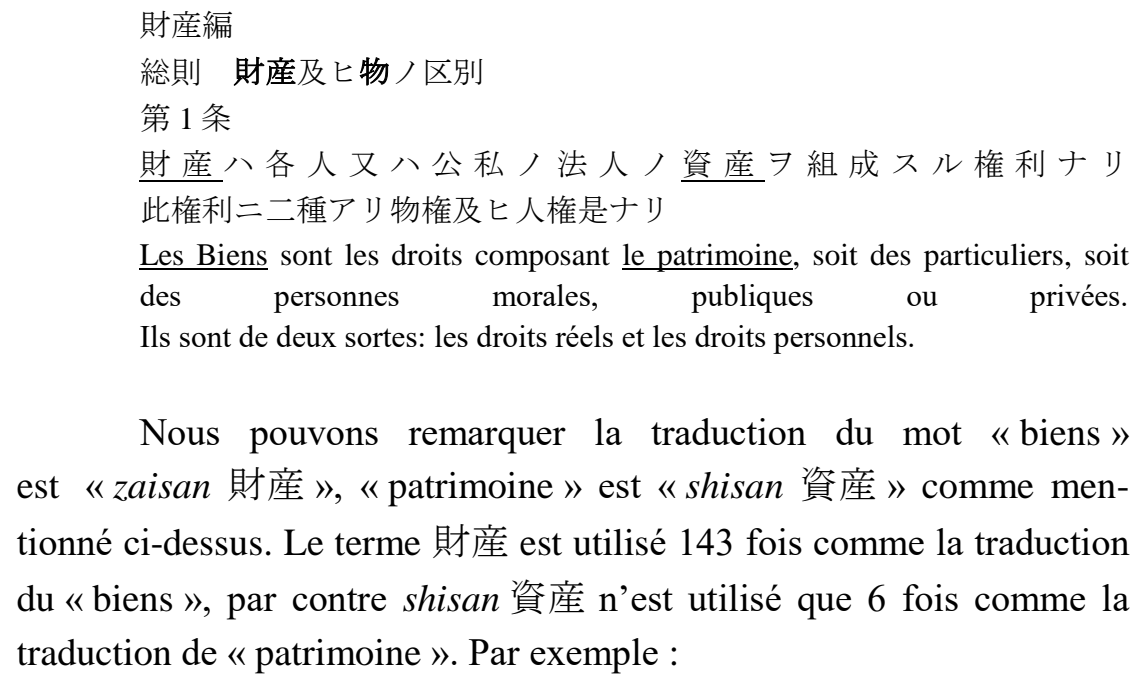

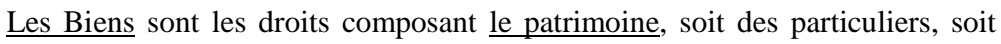
des personnes morales, publiques ou privées. Ils sont de deux sortes: les droits réels et les droits personnels.

Nous pouvons remarquer la traduction du mot «biens» est 《zaisan 財産》, 《 patrimoine» est 《shisan 資産》comme mentionné ci-dessus. Le terme 財産 est utilisé 143 fois comme la traduction $\mathrm{du}$ 《biens », par contre shisan 資産 n'est utilisé que 6 fois comme la traduction de « patrimoine». Par exemple :

LIVRE DE L' ACQUISITION DES BIENS. Article 61 Paragraphe (3)

旧民法 財産取得編 第六十一条 第三項 
Le vendeur qui, aux termes de l' article 478 du Livre des Biens a usé du droit de retirer les sommes consignées ne peut invoquer une seconde fois la faculté accordée par le présent article.

供託シタル金額习引取ルノ権利习財産編第四百七十八条二従ヒテ行使 シタル売主八再ヒ本条ノ許与セル権能习援用スルコトヨ得ス

LIVRE DE L' ACQUISITION DES BIENS. Article 177 Paragraphe (2) 旧民法 財産取得編 第百七十七条 第二項

Toutefois, en cas de décès de cette personne, par une cause illégitime imputable au débiteur, si la rente a été constituée à titre onéreux ou comme charge d'une donation ou d'un legs, le contrat ou la libéralité seront résolus et le débiteur restituera les biens acquis par lui, sans recouvrer les arrérages payés.

然レトモ終身ヨ期セラレタル人カ債務者ノ責二帰ス可キ不正ノ原因二 由リテ死亡シタル場合二於テ其年金権ヨ有償ニテ又ハ贈与若ク八遺贈 ノ負担トシテ設定シタリシトキハ其契約又八恵与ハ之ヨ解除ス且債務 者ハ既二支払ヒタル年金ヨ取戻サスシテ其取得シタル財産习返還スル コトヨ要ス

\section{旧民法 財産編 第四十六条 第二項}

LIVRE DES PREUVES. Article 46 Paragraphe (2)

又用益権八他ノ用益権ノ上、終身年金権ノ上又八包括権原二テ資産ノ 上ニ之ヨ設定スルコトヨ得

Il peut aussi être établi sur un autre usufruit, sur une rente viagère ou sur un patrimoine à titre universel.

\section{旧民法 財産編 第十六条 第一項}

LIVRE DES PREUVES. Article 16 Paragraphe (1)

第四 包括財産即千相続ノ総動産若ク八総不動産又八相続ノ全部若ク 八一分ノ如キ資産ノ全部又ハ一分习組成スル物

$4^{\circ}$ Comme universalité de biens formant tout ou partie d'un patrimoine; tels que tous les meubles ou tous les immeubles d'une succession, ou la succession tout entière, ou une quote part des mêmes biens.

Ensuite, nous aimerions bien comparer avec le texte original proposé par Gustave Emile Boissonade de Fontarabie ci-dessous ;

Version en japonais :

財産編 


\section{総則 財産及七物ノ区別}

第 1 条

財産八各人又八公私ノ法人ノ資産 7 組成スル権利ナリ 此権利二二種アリ物権及七人権是ナリ

La traduction officielle en français :

Les Biens sont les droits composant le patrimoine, soit des particuliers, soit des personnes morales, publiques ou privées. Ils sont de deux sortes: les droits réels et les droits personnels.

le texte original proposé par Gustave Emile Boissonade de Fontarabie :

Dispositions préliminaires de la division de biens et de choses

Les Biens ou droits composant le patrimoine, soit des particuliers ou des corporations, soit de l'Etat, des départements, des communes, ou des établissements publics sont de deux sortes: les droits réels et les droits personnels.

財産 /Les Biens / Les Biens

権利ナリ/ sont le droit / ou droits

組成スル / composant / composant

資産 / le patrimoine / le patrimoine

soit

各人 / des particuliers, / des particuliers

又八 $/ \mathrm{ou} / \mathrm{ou}$

公私ノ法人 / des personnes morales, publiques ou privées / des corporations, soit de l'Etat, des départements, des communes, ou des établissements publics

アリ/ sont / sont

二種 / de deux sortes / de deux sortes

物権 / les droits réels / les droits réels

及七 et / et

人権 les droits personnels / les droits personnels

Nous pouvons remarquer la différence de la composition grammaticale de deux textes ; dans le texte original proposé par Boissonade de Fontarabie, le sujet est 'Les Biens ou droits', le prédicat (et le complément) est 'sont de deux sortes', par contre, dans le texte en japonais le sujet est 'les Biens' et le prédicat (et le complément) est 'sont les droits'. Pourquoi 'Les Biens ou droits composant le patrimoine' a été transformé par 'Les Biens sont les droits composant le patrimoine'? 
Quelle était la différence entre l'interprétation par Boissonade de Fontarabie et celle de Mitsukuri sur « les biens » et « le patrimoine»?

5. Le concept et la théorie du patrimoine et des biens dans le Code civil français Kyu-minpo 旧民法 (l'ancien Code civil)

À l'époque où Boissonade a rédigé le projet de l'ancien Code civil japonais, la théorie sur patrimoine par Aubry et Rau avait été largement acceptée en France. Le projet du Boissonade a été associé avec cette théorie d'Aubry et Rau, puisque Boissonade a considéré d'incorporer cette théorie sur patrimoine comme la base de l'ancien Code civil japonais. L'ancien Code civil a été donc rédigé à partir du point de vue de cette théorie, qui dit que le patrimoine est une universalité juridique liée à la personne.

Aubry et Rau présentent leurs idées en disant que «Le patrimoine est l'ensemble des biens d'une personne, envisagé comme formant une universalité de droit, c'est-à-dire une masse de biens qui, de nature et d'origine diverses, et matériellement séparés, ne sont réunis par la pensée qu'en considération du fait qu'ils appartiennent à une même personne. L'idée de patrimoine est le corollaire de l'idée de personnalité. » (Aubry et Rau , $1873: 229-230, \S 573$ Notion du patrimoine ${ }^{2}$ ).

Ils disent aussi que «le patrimoine étant une émanation de la personnalité, et l'expression de la puissance juridique dont une personne se trouve investie comme telle, il est en résulte : Que les personnes physiques ou morales peuvent seules avoir un patrimoine; Que toute personne a nécessairement un patrimoine, alors même qu'elle ne posséderait actuellement aucun bien; Que la même personne ne peut avoir qu'un seul patrimoine, dans le sens propre du mot» (Aubry et Rau

${ }^{2} \mathrm{http}: / /$ droit.wester.ouisse.free.fr/pages/brocantes/aubry_rau_patrimoine_1.htm 20 
1873 ; 231) et « le patrimoine est, en principe, un et indivisible, comme la personnalité même, non seulement au point de vue déjà indiqué à la fin de paragraphe précédent, et en ce que la même personne ne peut posséder qu'un seul patrimoine, mais encore en ce sens que le patrimoine d'une personne n'est pas, à raison de sa nature incorporelle, divisible en parties matérielles ou de quantité, et n'est pas même susceptible, à raison de l'unité de la personne, de se partager en plusieurs universalités juridiques, distinctes les unes des autres ». (Aubry et Rau, 1873; 232). Cela a pour conséquence que le patrimoine ne peut être cédé entre vifs, on ne peut juste que céder des éléments, aucunement la vocation de droit. Il n'est transmissible qu'en cas de mort.

Une autre notion qui est essentielle de la théorie de Aubry et Rau est que « le patrimoine, considéré comme ensemble, de bien ou de valeur pécuniare, exprime lui-même, en définitive, l'idée d'une pareille valeur. Pour en déterminer la consistance, il faut, de toute nécessité déduire le passif de l'actif » (Aubry et Rau, 1873 ; 231).

En ce qui concerne le terme «biens » qui constitue «le patrimoine ", dans le Code civil français de 1804, la notion de ce terme est définie dans « le Livre II Des biens et des différentes modifications de la propriété, Titre Ier De la distinction des biens » : «Tous les biens sont meubles et immeubles. » (article 516 ${ }^{3}$ ). Puisque le Code civil français a adopté le système Institutiones, contrairement au droit romain qui plutôt définit une « chose » directement, est caractérisée par la définition de la classification des biens. Généralement, selon le dictionnaire du droit privé, le terme « biens » se définit ainsi, c'est-à-dire « que la totalité des meubles et des immeubles appartenant à une personne : l'ensemble de ses biens et de ses droits et actions constitue son patrimoine ${ }^{4} \gg$. L'article 16 de l'ancien Code civil japonais se définit par la relation entre les choses et les biens de façon tout à fait pareil ${ }^{5}$ :

\footnotetext{
${ }^{3} \mathrm{http}: / / \mathrm{www}$.assemblee-nationale.fr/evenements/code-civil/cc1804-12t01.pdf

${ }^{4} \mathrm{http}: / / \mathrm{www}$.dictionnaire-juridique.com/definition/biens-les.php

${ }^{5}$ Le Code civil d'aujoud'hui définit « une chose » que «この法律において「物」と は、有体物をいう。Dans la présente loi, 'une chose' se réfère à un objet tangible. » et qu'il n'y a pas la définition que Boissonade avait proposée.
} 
le texte original proposé par Gustave Emile Boissonade de Fontarabie : « Les choses peuvent être envisagées, soit comme objets individuels ou corps certains, tels qu'une maison, un champ, un animal; soit comme quantités déterminées, au poids, au nombre ou à la mesure; soit comme collection d'objets plus ou moins semblables et susceptibles d'augmentation ou de diminution; tels qu'un troupeau, les livres d'une bibliothèque, les marchandises d'un magasin; soit enfin comme universalité de biens formant tout ou partie d'un patrimoine, tels que: tous les meubles ou tous les immeubles d'une succession, ou la succession toute entière, ou une quote part des mêmes biens. »

Texte en japonais :

物八左, 如 之

第一特定物即チ某家、某田、某獣ノ如キ殊別ナル物

第二 定量物即チ金幾円、米幾石、布幾反ノ如キ数量尺度ヨ以テ算フ

ル 物

第三 聚合物即チ群畜、書庫ノ書籍、店舗ノ商品ノ如キ増減シ得へキ

多少類似少物

第四 包括財産即千相続ノ総動産若クハ総不動産又ハ相続ノ全部若ク ハ一分ノ如キ資産ノ全部又ハ一分ヨ組成スル物

La traduction officielle en français:

«Les choses peuvent être envisagées:

$1^{\circ}$ Comme corps certains; tels qu'un objet spécifié, comme une maison, un champ, un animal;

$2^{\circ}$ Comme quantités, en poids, nombre ou mesure; tels qu'une somme d'argent, des kokou de riz, des tan d'étoffe;

$3^{\circ}$ Comme collection d'objets plus ou moins semblables et susceptibles d'augmentation ou de diminution; tels qu'un troupeau, les livres d'une bibliothèque, les marchandises d'un magasin;

$4^{\circ}$ Comme universalité de biens formant tout ou partie d'un patrimoine; tels que tous les meubles ou tous les immeubles d'une succession, ou la succession tout entière, ou une quote part des mêmes biens. "

Plus simplement, les biens sont les choses qui peuvent devenir la propriété d'une personne, c'est-à-dire, les choses qui sont appréhendées par le droit.

Ce qui est caractéristique dans le code civil français et qui est différent que le code civil japonais, c'est qu'il existe des objets qui n'existent que par et dans le système juridique. Ces objets, ce sont les 
droits qui sont créés à l'intérieur même du système juridique et par des techniques juridiques. Ces droits (par ex. une créance de somme d'argent) manifestent des liens entre plusieurs personnes et sont également des biens lorsqu'ils acquièrent une valeur qui les destinent à circuler d'un patrimoine à un autre ${ }^{6}$.

Comme conclusion, je suppose que la raison pour laquelle les textes proposés par Boissonade ont été traduits autrement, est justement parce que cette notion distinctive du Code civil français, c'est- à-dire que les biens inclus non seulement les choses mais aussi le droit des personnes, n'a pas été bien compris par les Japonais. Notre conjecture donne la réponse de la question pourquoi l'article $1^{\text {er }}$ de l'ancien Code civil japonais définit qu' «Ils (les biens) sont de deux sortes: les droits réels et les droits personnels ».

\section{Le trait caractéristique de la traduction des « biens » et $\mathrm{du}$ « patrimoine » en japonais}

Mitsukuri a forgé le terme «zaisan 財産》 comme la traduction du mot biens et «shisan 資産》 comme la traduction du «patrimoine ». Cependant, aujourd'hui ces deux termes français sont traduit de façons très variées :

la traduction du «bien »: zaisan 財産、zai 財、butsu物、zaibutsu 財物、 la traduction du «patrimoine » : shisan 資産、kasan 家産、zaisantai 財産体、 kahou 家宝、isan 遺産.

Pour la traduction du « bien », les idéogrammes zai 財, butsu物, $s a n$ 産 sont utilisés en composition. Zai 財 veut dire 'quelque chose de précieux', butsu物 signifie 'une chose'. San 産 est aussi utilisé pour la

6 http://www.univag.fr/modules/resources/download/default/UFR_SJE/Plans_de_cours/ Droit_des_biens_support_1ere_partie.pdf 
traduction du "patrimoine », cet idéogramme signifie 'la naissance'. Cela dit, si une femme donne la naissance, ce serait un bébé, si quelqu'un donne la naissance de l'argent (faire de l'argent), ce serait la fortune. La composition des deux idéogrammes zaisan 財産 veut dire 'quelque chose de précieux, qui a été fait'. D'autres compositions shisan 資産 veut dire 'shi 資 ceux qui sous-tend, san 産 qui a été fait', autrement dit 'actif'. kasan 家産 veut dire de la même façon, ' $k a$ 家 maison, famille ou quelque chose qui appartient à la famille, san 産 qui a été fait', cela dit 'propriété familiale'. Isan 遺産 veut dire ' $i$ 遺 laisser quelque chose, donner quelque chose par exemple, après la mort, san 産 qui a été fait'. Ce qui est intéressant comme la traduction du patrimoine est utilisé zaisan 財産 et tai 体. Zaisan 財産 est considéré comme la traduction du «bien » et tai 体 signifie 'le corps de quelqu'un, la nature (essence) de quelque chose, la forme' cela dit littéralement ' la nature (essence) des biens'. Dans le dictionnaire de droit français, «bien» est décrit comme suivant:

1.一般的に財。土地、家屋、債権、地役権、用益権など、Patrimoine を構成する物、価值、又は権利。

En général zai 財 (quelque chose de précieux). Des terrains, des maisons, des prêts, des servitudes, l'usufruit, etc., ce qui constitue un patrimoine, la valeur ou le droit.

2. (狭義) （所有、占有の対象となり得る）優待財産。

(Sens étroit) la propriété préférentielle, qui peut devenir le sujet de l'occupation des biens.

Par contre, « le patrimoine » est décrit comme suivant :

1. ある者の総資産としての家産。ある者の法的総資産（包括財産）

universalité を形成し、積極財産 actif 及び消極財産 passif から成る、そ の現在および将来の動産及び不動産の総体。

Propriété familiale qui est l'actif total de la personne. L'ensemble de l'immobilier et le mobilier actuels et futurs, qui est constitué d'actif et de passif, et un total de l'universalité juridique ( les biens inclus).

2 . 特定の目的のための特定財産体

Corps de propriété spécifique à un usage particulier.

3. 文化遺産などの人類共通財産、文化財。

Propriété de l'humanité, les biens culturels et du patrimoine culturel. 
7. Conclusion : «les biens » et «le patrimoine». L'étude du point de vue linguistique

Comme la description ci-dessus, la traduction des termes « les biens » et « le patrimoine » est très variée et l'explication selon le dictionnaire est trop compliquée pour saisir le sens global des mots.

En revenant encore une fois au sens original du terme français; « tous les biens sont meubles et immeubles. » et que «les biens sont les choses qui peuvent être devenir la propriété d'une personne », nous supposons que «les biens» doivent être traduits comme 財産. D'autre part, « le patrimoine » signifiait à cette époque-là «l'ensemble des biens d'une personne, envisagé comme formant une universalité de droit». Si « les biens » sont traduits comme 財産, « le patrimoine » doit être 'l'ensemble de 財産', cela dit 《財産体》. Nous supposons que l'idéogramme 体 est convenable pour exprimer « l'ensemble ».

Les mots essentiels du Code civil, dont beaucoup ont été traduits du français, sont fréquemment utilisés dans la vie quotidienne. Cependant, un nouveau concept qui n'avait pas existé au Japon auparavant était très difficile à comprendre pour les Japonais. Par conséquent, les mots étaient forgés et utilisés tandis que la plupart des gens ne comprenaient pas ce que ça voulait dire. En ce sens, on peut dire qu'il faut comprendre encore une fois le sens des mots de la langue d'origine et trouver la traduction appropriée.

La création du Code civil japonais par la traduction du Code Napoléon a donné l'occasion aux Japonais de connaître des idées nouvelles qui n'existaient pas à l'ère Meiji. L'introduction du concept de l'Europe était non seulement le moment de lier avec l'Europe, mais aussi le moment de former et de constituer un nouveau concept pour les Japonais. Cette formation de droit et des terminologies ne s'est pas terminée à l'ère Meiji. Au XXI ${ }^{\mathrm{e}}$ siècle, pour l'avenir de la poursuite du développement du droit japonais, on peut dire qu'il est très important de considérer le langage juridique en général. 
8. Bibliographie

Aizawa S. 相沢幸夫.1987. Hōritsu yōgo taiyaku shū 法律用語対訳集. Tokio: Shōji hōmu kenkyūkai 商事法務研究会.

Alcaraz E., Hughes B. 2002. Legal Translation Explained. Manchester. Svol. Jerome Publishing.

Delisle J. (et al., ed.). 1999. Translation Terminology. Amsterdam/Philadelphia : John Benjamins Publishing Company.

Furuta H. 古田裕清 2005. Honyakugo tositeno nihon no hōritu yōgo 翻 訳語としての日本の法律用語. Tokio: Chūō shuppanbu 中央 出版部.

Gōhara T. 郷原豊茂 2006. Minpō sōsoku bukken hen 民法総則物件編. Tokio: TAC shuppansha TAC 出版社.

Gōhara T. 鄉原豊茂. 2006. Minpō no marugoto kōgi namachūkē 民法 の丸ごと講義生中継. Tokio: TAC shuppansha TAC 出版社.

Hashiuchi T. 橋内武. Hotta S. 堀田秀吾. Hō to gengo 法と言語. Tokio: Kuroshio shuppan くろしお出版.

Hoshino E. 星野英一. 1998. Minpō no susume 民法のすすめ. Tokio: Iwanami shinsho 岩波書房.

Ishimito, M. 1954. L'influence du Code civil français sur le droit civil japonais. [In:] Revue internationale de droit comparé. Vol. 6/4, 744-752. doi: 10.3406/ridc.1954.9093.

Kawaguchi Y. 川口由彦. Nihon kindai hōseishi. 日本近代法制史. Tokio: Shinsēsha 新世社.

Kitamura I. 2006. Furansu minpōten no nihyaku nen フランス民法典 の二百年 Le bicentenaire du Code civil Français. Tokio: Yūhi$\mathrm{kaku}$ 有斐閣

Lerat P. 2007. Vocabulaire du juriste débutant. Paris: PUF.

Murakami J. 村上淳一. 2005. ho no rekishi 法の歴史. Tokio: Tokyo daigaku shuppankai 東京大学出版会. 
Nisida T. (ed.) 2003. 言語学を学ぶ人のために(Gengogaku o manabu hito no tameni). Kyoto: Sekai shisōsha.

Ōmura A. 大村敦. 2001. Kihon minpō 基本民法. Tokio: Yūhikaku 有 斐閣

Ōmura A. 大村敦. 2007. Minpō zero, iti, ni, san zyō. <Watasi > ga ikiru rūru「民法 0.1．２．３条」く私＞が生きるルール. Tokyo: Misuzu syobō みすず書房.

Ōmura A. 大村敦. 2010. Furansu minpō フランス民法. Tokio: Shinzan sha 信山社

Sacco R. 1999. «Langue et droit ». Les multiples langues du droit européen uniforme. Torino: L'Harmattan.

Saitō T. 2005. 明治の言葉 (Meiji no kotoba). Tokyo: Kōdansya gakuzyutu bunko.

Sójka-Zielińska K. 2008. Kodeks Napoleona. Historia i współczesność. Warszawa: LexixNexis.

Takanasi K. red. 2006. Kōgo roppō zensho kōgo mimpō 口語六法全書 口語民法. Tokio: Ziyūkokuminsha 自由国民社.

Uchida T. 内田貴. 1994. 民法 I-V MinpōI-V. Toki: Tokyo daigaku shuppankai.

Yamaguchi T. 2002. フランス法辞典 (dictionnaire du droit français). Tokyo: Tōkyō daigaku shuppan kai.

Yamamoto K. 2000. 公序良俗論の再構成 (Kōjo ryōzoku ron no saikōsē). Tokyo: Yūsenkaku.

Yokoi H. 横井秀明. 2007. Jitsuyōban hōritsu yōgo no kisochishiki 法律 用語の基礎知識. Tokiyo: Jiyū kokuminsha 自由国民社.

http://www.law.nagoya-u.ac.jp/jalii/arthis/index.html 